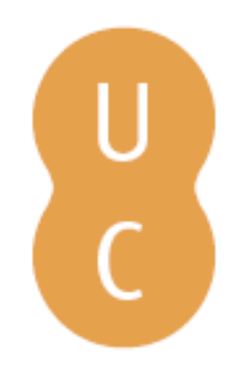

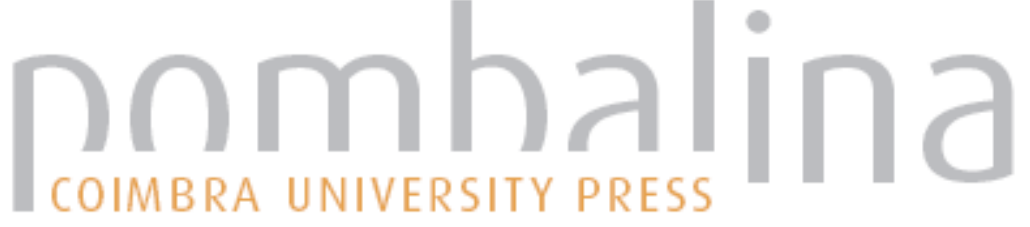

\section{O Cadastro Ambiental Rural como nova etapa do planejamento territorial ambiental brasileiro}

\author{
Autor(es): $\quad$ Santos, João Paulo de Faria \\ Publicado por: Imprensa da Universidade de Coimbra \\ URL \\ persistente: URI:http://hdl.handle.net/10316.2/37061 \\ DOI: $\quad$ DOI:http://dx.doi.org/10.14195/978-989-26-0983-6_8 \\ Accessed : $\quad$ 26-Apr-2023 14:09:59
}

A navegação consulta e descarregamento dos títulos inseridos nas Bibliotecas Digitais UC Digitalis, UC Pombalina e UC Impactum, pressupõem a aceitação plena e sem reservas dos Termos e Condições de Uso destas Bibliotecas Digitais, disponíveis em https://digitalis.uc.pt/pt-pt/termos.

Conforme exposto nos referidos Termos e Condições de Uso, o descarregamento de títulos de acesso restrito requer uma licença válida de autorização devendo o utilizador aceder ao(s) documento(s) a partir de um endereço de IP da instituição detentora da supramencionada licença.

Ao utilizador é apenas permitido o descarregamento para uso pessoal, pelo que o emprego do(s) título(s) descarregado(s) para outro fim, designadamente comercial, carece de autorização do respetivo autor ou editor da obra.

Na medida em que todas as obras da UC Digitalis se encontram protegidas pelo Código do Direito de Autor e Direitos Conexos e demais legislação aplicável, toda a cópia, parcial ou total, deste documento, nos casos em que é legalmente admitida, deverá conter ou fazer-se acompanhar por este aviso.

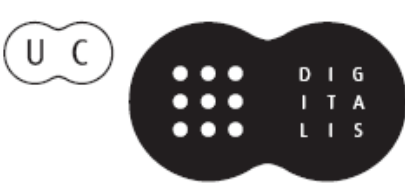




\section{$\forall$ \\ TAS DAS I JORNADAS LUSÓFONAS DE CIÊNCIAS E TECNOLOGIAS DE INFORMAÇÃO GEOGRÁFICA}

Editores

José Gomes dos Santos

Cidália Fonte

Rui Ferreira de Figueiredo

Alberto Cardoso

Gil Gonçalves

José Paulo Almeida

Sara Baptista 


\title{
ARTIGO 8 \\ O CADASTRO AMBIENTAL RURAL COMO NOVA ETAPA DO PLANEJAMENTO TERRITORIAL \\ AMBIENTAL BRASILEIRO
}

SANTOS, João Paulo de Faria

\author{
Diretor do Departamento de Apoio ao Conselho Nacional do Meio Ambiente \\ Ministério do Meio Ambiente (Brasil) \\ Esplanada dos Ministérios, Bloco "B" - $9^{\circ}$ Andar \\ 70.068-900 Brasília - DF - Brasil \\ Tel: +51 61 2028-1358; e-mail: joao.santos@mma.gov.br
}

\section{RESUMO}

Esse artigo curto se propõe a apresentar as inovações jurídicas e possibilidades institucionais que se consolidaram com a instituição do Cadastro Ambiental Rural (CAR) no Brasil, nacionalmente criado pela Lei 12.651/2012. Em especial, firma-se a convicção de que o planejamento territorial é, finalmente, levado a sério no Brasil, com novos instrumentos cartográficos e jurídicos, modificando o paradigma do controle e fiscalização das infrações ambientais. Por fim, o autor se propõe a apresentar os passos ainda necessários de normatização e hermenêutica fundamentais para que o CAR cumpra o seu papel.

\section{PALAVRAS-CHAVE}

Controle ambiental, Direito ambiental, Código florestal brasileiro, Cadastro ambiental, Planejamento territorial. 


\title{
THE AGRARIAN ENVIRONMENTAL REGISTRY AS A \\ NEW STAGE OF THE BRAZILIAN ENVIRONMENTAL
}

TERRITORIAL PLANNING

\begin{abstract}
This short paper aims to present legal innovations and institutional possibilities that have been consolidated with the establishment of the Agrarian Environmental Registry (CAR) nationally created by the Law $12.651 / 2012$, in Brazil. In particular, it shows the conviction that territorial planning has finally been taken seriously in Brazil, with new map and legal instruments, changing the paradigm of command and control of environmental violations. Finally, the author presents steps that are still necessary to regulation and fundamental hermeneutic for CAR to fulfill its role.
\end{abstract}

\section{KEYWORDS}

Environmental control, Environmental law, Brazilian forest code, Environmental registry, Territorial planning

\section{INTRODUÇÃO}

O Cadastro Ambiental Rural (CAR), criado nacionalmente pelo art. 29 da Lei 12.651, de 25 de maio de 2012 (conhecida como Novo Código Florestal Brasileiro), foi um dos poucos pontos - quiçá o único - aclamados como avanço ambiental da nova lei florestal brasileira. ${ }^{1}$ Em vários aspectos, essa aclamação tem uma razão de ser sub-reptícia de mudança paradigmática, na qual o combate ao ilícito ambiental entra em uma fase de diversificação de instrumentos e, especialmente, ganha um formato mais estratégico, baseando-se no planejamento e conhecimento do território. O CAR, em conjunto com o Novo Código Florestal, está inaugurando, ou consolidando, uma nova política ambiental, menos baseada no comando e controle e mais em um geodireito que se pauta inexoravelmente na participação democrática sobre os destinos e usos do território.

\footnotetext{
1 "Apesar das inúmeras críticas que o novo Código Florestal Brasileiro recebeu durante sua tramitação no Congresso Nacional, pelo menos no que se refere ao Cadastro Ambiental Rural houve um avanço significativo da legislação" (TRENNEPOHL, 2012, 299)
} 


\section{APRESENTAÇÃO DO TEMA}

Nesse sentido, a tese principal do presente artigo - de que o Cadastro Ambiental Rural (CAR) é um marco de transição, na política ambiental brasileira, do mero comando e controle para um geodireito planejado - parte de uma análise histórica das demais legislações florestais que vigoraram no Brasil ao longo do Século XX. O início de nossa argumentação estará ancorada em uma análise histórica mais além dos dispositivos e mecanismos de controle, colocando luzes na (falta de) legitimidade e cosmovisões silentes.

No debate dessas cosmovisões, analisaremos, por um lado, conceitos e preconceitos que permearam a vigência de leis ambientais repressivas e, por outro, a forma como o Código Florestal e o Cadastro Ambiental Rural (CAR) terminam por oferecer outra visão sobre o problema ambiental, partindo de pressupostos socioeconômicos preocupados com o planejamento territorial.

A partir disso, o debate ocorrerá também ao relacionar o CAR (no contexto do Código Florestal) como um amadurecimento administrativo que percebe a questão ambiental como um espaço econômico a necessitar de múltiplos instrumentos estatais. Instrumentos estatais que não sejam somente repressivos, mas também, e especialmente, indutivos, chamados de incentivos econômicos pela Lei 12.651/2012.

A seguir, o artigo passa a apresentar dados atuais de instalação do sistema do Cadastro Ambiental Rural, em especial informações técnicas necessárias à sua ativação. Insere ainda o CAR no Sistema Nacional de Informação sobre Meio Ambiente (SINIMA) e traz dados mais precisos sobre o geocatálogo do Ministério do Meio Ambiente e suas regras jurídicas de utilização.

Por fim, o artigo se volta a refletir sobre os passos ainda a serem trilhados para a efetivação do Cadastro Ambiental Rural no Brasil.

\section{METODOLOGIA UTILIZADA}

A metodologia utilizada no artigo, típica das ciências sociais, parte 
de estudo referencial de fontes bibliográficas primárias e secundárias, além de análise hermenêutica ambiental da normas legais e infra-legais brasileiras típica do direito.

\section{APRESEnTAÇÃo dos dAdos: histórico da LegislaÇÃo FLORESTAL BRASILEIRA}

A Lei 12.651/2012, conhecida como Novo Código Florestal Brasileiro, passou por mais de uma década de debates e votações no Congresso Nacional, ganhando assim a característica de ser o primeiro Código Florestal da República Brasileira com contornos democráticos e constitucionais, inserindo-se no debate parlamentar de forma exaustiva.

Bom resumo do longo trâmite legislativo nos trazem Leuzinger e Cureau (2013, 163-164), cujos pontos centrais da narração inicial e final reproduzimos:

"Em 19/10/1999, o Deputado Sérgio Carvalho, do PSDB/RO, apresentou o Projeto de Lei $\mathrm{n}^{\circ} 1876$ ao Congresso Nacional, que revogava o Código Florestal de 1965 e alterava a Lei de Crimes Ambientais. [...] Após diversos incidentes, o PL foi votado pelo Plenário em 11/05/2011, quando foram apresentadas 186 Emendas de Plenário. [...] Em 24/05/2011, foi aprovada a redação final, assinada pelo Relator Aldo Rebelo [...] Em 25 de maio de 2012, a redação final do PL foi transformada na Lei ordinária n ${ }^{\circ} 12.651$ ”.

Cumpre ressaltar que, após o debate no Parlamento, se seguiu uma ativa participação da Presidenta da República Dilma Rousseff, tanto por meio de vetos parciais quanto pela edição complementar da Medida Provisória 571, de 25 de maio de 2012, posteriormente convertida na Lei $12.271 / 2012$.

Com diferente trâmite, as legislações florestais anteriores, que se pautavam de forma exclusiva em um comando e controle rígido, uma fiscalização intensa e um paradigma silente de que a questão ambiental no fundo seria meramente moral, foram todas construídas em regimes 
autoritários. Assim o foi o Decreto 23.793, de 23 de Janeiro de 1934, editado pelo governo provisório de Getúlio Vargas, sem participação do parlamento. De igual forma, o foi a Lei 4.771, de 15 de setembro de 1965, publicada já no período da ditadura militar brasileira pelo Presidente Marechal Humberto Castello Branco, diante de um Congresso acertadamente temeroso e que veria extinto o pluripartidarismo e desativados todos os partidos políticos no mês seguinte à aprovação do Código Florestal, com a edição, pela ditadura, do Ato Institucional $n^{\circ} 2$. O clima democrático estava distante daquele Parlamento amedrontado de então.

Essa forma de edição de leis ambientais não foi isoladamente estabelecida pelas duas leis citadas, mas seguia um padrão repetido pela maioria das leis e códigos referentes ao meio ambiente. ${ }^{2}$ A discussão não era democrática e o território e seus usos eram assuntos dos ditadores da época ou, no máximo, de especialistas tecnocráticos, nunca objeto do debate democrático.

Na prática, isso definia uma legislação e um aparelhamento estatal que tratava a questão ambiental, especialmente a questão agroambiental, como questão de polícia, buscando endurecer cada vez mais a fiscalização, a fim de corrigir um problema resumido a mero desvio de conduta.

Nem mesmo a modernização da administração pública empreendida pelo Governo Fernando Henrique Cardoso (1994-2002) conseguiu demolir a mentalidade meramente punitiva - e ineficaz - que imperava na administração ambiental. Somente com o advento da Lei 12.651/2012, em trâmite desde a época do Presidente Fernando Henrique, foi possível trazer novas luzes ao tema, especialmente por seu intenso debate com a maioria dos agentes econômicos envolvidos, especialmente os empreendedores rurais.

Essa multiplicidade de interesses, possibilitada por um geodireito (aqui entendido como o espraiamento no território dos direitos fundamentais, entre os quais o direito a um meio ambiente sustentável) que se dispunha a discutir o território democraticamente, criou condições para que a era

2 No mesmo sentido, aprovado pela Ditadura de Vargas, o Código de Águas (Dec. 24.643/34), o Código de Minas (Dec. 24.642/34). Já na vigência da Ditadura Militar, foram editadas a Lei de Fauna (Lei 5.197/67), a Lei de Criação do IBDF, Instituto Brasileiro de Desenvolvimento Florestal (Dec. 289/77), e a Lei da Secretaria Especial de Meio Ambiente (Dec. 73.030/70). 
posterior ao Novo Código Florestal, em suas necessárias regulamentações, se posicionasse como marco zero da gestão ambiental brasileira. Em primeiro lugar, por trazer novos princípios como o da isonomia ripária (corolário do princípio da Rio-92 das responsabilidades comuns, porém diferenciadas) e, em segundo, por entender o empreendedor rural como um agente econômico como outro qualquer, confrontado com aspectos socioeconômicos em sua tomada de decisão. Sob esses pressupostos, impôs-se a necessidade de um planejamento territorial de usos economicamente sustentáveis para a população e para o setor empresarial rural.

\section{Discussão dos Resultados: A Lei 12.651/2012 E O CAdASTRO Ambiental RURAL, UMA NOVA POLítica AMbiental}

A inauguração de uma nova política ambiental, orientada para o planejamento territorial estratégico, tem seu histórico marcado pela onda constitucional verde (Portugal em 1976 - artigo 66, 2, b - e Grécia em 1975 - artigo 24,2) e tem, na indução de certas atividades em certas áreas conhecidas e priorizadas, seu eixo estruturante.

A Lei 12.651/2012 visivelmente busca isso, diminuindo o enfoque do comando e controle e construindo instrumentos econômicos que se preocupem com a aplicabilidade e a eficácia da legislação ambiental.

É nesse sentido que o CAR se torna pressuposto dessa política. Quando se deseja a superação do monopólio da política do comando e controle (uma espécie de 'Leviatã' ambiental, sempre antidemocrático, como visto na história brasileira), o desafio governamental deve se centrar na precisão das informações. Não haverá planejamento no Brasil sem que se conheçam as mais de 5 milhões de propriedades rurais no território nacional. Nesse sentido, afirma Trennenpohl, 2012, 295: “o desconhecimento das propriedades rurais no Brasil, em termos de titularidade, limites físicos e características ambientais era uma das maiores fragilidades para o planejamento e a implementação efetiva de políticas de governo, tanto na defesa do meio ambiente quanto na produção agropecuária”.

Assim, a construção de um cadastro ambiental passa primeiro pela obtenção de maior qualidade nas informações geoespaciais do território 
brasileiro. O sensoriamento remoto via satélite foi, então, aprimorado pela inclusão do Cadastro Ambiental Rural, por força do art. 29 da Lei 12.651/2012, no SINIMA (Sistema Nacional de Informação sobre Meio Ambiente), com o objetivo de agregar o CAR como reforço ao acesso à informação ambiental (SARLET \& FENSTERSEIFER, 2014). A inserção no SINIMA, além disso, gerou a integração nacional do sistema (anteriormente já haviam existido no Brasil 21 experiências de cadastros ambientais, sempre no âmbito estadual) e trouxe a possibilidade da compra de novas imagens, por meio do Contrato MMA 30/2012.

Essas imagens formam o Geocatálogo do Ministério do Meio Ambiente, que conta com os resultados mais precisos (escala 1:5m) dos chamados satélites Rapid Eye, em órbita desde 2008. Essas imagens foram importantes para a formação de um cadastro útil por: 1) coincidirem com o marco temporal do novo Código Florestal de 22 de julho de 2008 (art. $59, \S 4^{\circ}$ ) e 2) terem um preço acessível à administração pública, tendo em vista serem imagens de catálogo, com um ano de defasagem. Isso possibilitou, inclusive, ao Ministério do Meio Ambiente, uma quebra do monopólio de compras de imagens, com o compartilhamento com outros órgãos e entidades federais e estaduais.

O Cadastro Ambiental Rural, então, com a superação de requisitos técnicos já concluída, entrará em vigor por ato do Ministro do Meio Ambiente, após oitiva do Ministério do Desenvolvimento Agrário e do Ministério da Agricultura (art. 21 do Decreto 7.830, de 17 de outubro de 2012), ainda não editado até a presente data. Nas palavras de Lehfeld et al. (2013, 193): "Muito embora tenha sido fixado prazo para que os proprietários de imóveis rurais promovessem o seu registro no CAR, o marco inicial desse prazo, que é a implantação do cadastro, não teve um momento definido pela lei, destacando o Decreto 7.830/2012 apenas o ato do Ministro do Meio Ambiente que definirá a data a partir da qual será considerado implantado o CAR”.

A partir dessa vigência, o CAR terá consequências diretas no comando e controle, trazendo a vedação a novas supressões e a impossibilidade de quaisquer créditos agrícolas a imóveis não cadastrados (art. 78-A da Lei 12.651/2012). A limitação creditícia agrária coaduna com a perspectiva dos 
Princípios do Equador e, no Brasil, desde a Circular BACEN 3547/2011, da contabilidade dos riscos ambientais pelas instituições financeiras.

Todavia, as principais consequências do Cadastro Ambiental Rural estarão voltadas à indução econômica, ou seja, à possibilidade de incentivos econômicos em um "esverdeamento" da política agrícola brasileira:

\footnotetext{
"Dessa forma, pode-se afirmar que o conhecimento da localização das propriedades e posses rurais em todo o País terá uma utilidade significativa para o planejamento de políticas públicas de proteção ambiental; mas, certamente, também servirá de insumo importante para direcionar investimentos e incentivos governamentais, planejar obras de infraestrutura e prever a expansão de novas fronteiras de crescimento da atividade produtiva" (TRENNEPOHL, 2012, 295)
}

Nesse sentido, além de incentivos tributários novos (art. 41, III da Lei 12.651/2012), o Código Florestal atual traz, para os cadastrados no CAR, a possibilidade de pagamento de serviços ambientais em várias formas (art. 41 da Lei 12.651/2012). E a principal delas estará voltada à compensação da reserva legal, em que um passivo de espaço ambiental a ser protegido em uma propriedade poderá ser compensado em outra, formando um mercado verde a remunerar a proteção ambiental. Todavia, assim como a vigência do CAR, o efetivo pagamento desses serviços ambientais também depende de regulamentação infra-legal do Poder Executivo Federal ainda não editada.

\section{CONCLUSÃo}

Nesse sentido, conclui-se que o Cadastro Ambiental Rural trará novas possibilidades de planejamento territorial democrático, inaugurando uma nova visão de geodireito na política ambiental brasileira. Já contando com recursos suficientes do ponto de vista técnico e geoespacial, correta está a noção, se entendida do ponto de vista estritamente jurídico, explanada por Antunes (2013, 185): "É um instrumento importante, porém, ainda longe da implementação necessária”. Não há como negar que ainda há alguns avanços normativos a serem realizados, especialmente a edição 
de ato que dê vigência ao CAR.

A edição urgente desse decreto de vigência é hoje ato fundamental para que a visão de que é possível um aproximação mais socioeconômica e menos moralista/repressiva sobre a questão ambiental no meio rural prospere. É uma novidade histórica no Brasil e, como toda novidade, precisa de vontade política e empenho para que se consolide. Entretanto, finalizamos reafirmando que uma nova etapa de planejamento territorial ambiental está lançada no Brasil: uma nova inteligência ambiental é hoje possível, especialmente pela pactuação democrática da Lei 12.651/2012, envolvendo todos os setores, de consumidores a produtores agrícolas.

\section{BIBLIOGRAFIA}

ANTUNES, Paulo de Bessa (2013) - Comentários ao Novo Código Florestal. Atlas, São Paulo. 341 p.

LEHFELD, Lucas de Souza et al. (2013) - Código Florestal comentado e anotado. Método, $2^{\mathrm{a}}$ ed., São Paulo, 368 p.

LEUZINGER, Márcia \& CUREAU, Sandra (2013) - Direito Ambiental. Elsevier, Rio de Janeiro, 373 p.

SARLET, Ingo \& FENSTERSEIFER, Tiago (2014) - Democracia Participativa e Participação Pública como Princípios do Estado Socioambiental de Direito. Revista de Direito Ambiental, Vol. 73/2014, p. 47.

TRENNEPOHL, Curt (2012) - Do Cadastro Ambiental Rural, in: MILARÉ, Édis \& MACHADO, Paulo Affonso Leme (coord.): Novo Código Florestal, São Paulo, Editora Revista dos Tribunais, 512 p. 
Série Documentos

Imprensa da Universidade de Coimbra

Coimbra University Press

2015

- U M

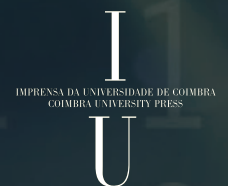

